\title{
Effects of 92\% oxygen administration on cognitive performance and physiological changes of intellectually and developmentally disabled people
}

\author{
Hyung-Sik Kim', Mi-Hyun Choi ${ }^{1}$, Ji-Hye Baek', Sung-Jun Park', Jung-Chul Lee', Ul-Ho Jeong ${ }^{1}$, Sung-Phil Kim², \\ Hyun-Jun Kim³ ${ }^{3}$ Y Young Chil Choi ${ }^{4}$, Dae-Woon Lim ${ }^{5}$ and Soon-Cheol Chung ${ }^{1 *}$
}

\begin{abstract}
Background: The present study addressed how 92\% oxygen administration affects cognitive performance, blood oxygen saturation $\left(\mathrm{SpO}_{2}\right)$, and heart rate (HR) of intellectually and developmentally disabled people.

Methods: Seven males (28.9 \pm 1.8 years) and seven females (34.4 \pm 8.3 years) with intellectual and developmental disabilities (disabled level $2.1 \pm 0.5$ ) completed an experiment consisting a 0-back task with normal air (21\% oxygen) administered in one run and hyperoxic air (92\% oxygen) administered in the other run. The experimental sequence in each run consisted of a 1-min adaptation phase, 2-min control phase, and 2-min 0-back task phase, where $\mathrm{SpO}_{2}$ and HR were gauged for each phase.

Results: The administration of 92\% oxygen increased 0-back task performance of intellectually and developmentally disabled people, in association with increased $\mathrm{SpO}_{2}$ and decreased $\mathrm{HR}$. Our results demonstrate that sufficient oxygen supply subserving cognitive functions, even as a short-term effect, could increase cognitive ability for the intellectually and developmentally disabled people.
\end{abstract}

Conclusions: It is concluded that enriched oxygen can positively affect, at least in the short-term, the working memory of those with intellectual and developmental disability.

Keywords: Oxygen administration, Cognitive performance, Blood oxygen saturation, Heart rate, Intellectual and developmental disability

\section{Background}

Intellectually and developmentally disabled people have difficulties in their social and personal lives as a consequence of insufficient or incomplete intellectual development due to the permanent retardation of physical and intellectual growth [1]. One of the most profound characteristics of those with intellectual and developmental disability is cognitive deficiency [1]. The cognitive impairment impairs information processing, problem solving, and attentive concentration [2-6]. Furthermore, the deficient capability in

\footnotetext{
* Correspondence: scchung@kku.ac.kr

${ }^{1}$ Department of Biomedical Engineering, BK21+ Research Institute of Biomedical Engineering, College of Biomedical \& Health Science, Konkuk University, 268 Chungwon-daero, Chungju Chungbuk-do 380-701, South Korea

Full list of author information is available at the end of the article
}

organizing informational units upon the simultaneous reception of myriad of information translates to memory deficiency $[2,4]$. Short-term and working memory are especially affected, rendering subjects forgetful of recently acquired information or learned tasks, as well as applying what they have learned in their daily lives [7] and in recalling information stored in memory [3].

The administration of high-concentration oxygen increases memory capability of healthy young and elderly individuals [8-12]. As well, exposure to highly concentrated oxygen positively affects $n$-back tasks, visuospatial perception, use of verbs, and efficiency in addition performance of healthy young adults [13-19]. Recently, external oxygen administration has been shown to have positive effects on 
visual matching task performance of intellectually and developmentally disabled individuals [20].

The administration of high-concentration oxygen also leads to cognitive enhancement, as revealed by increases in accuracy $[8,10,11,13-18]$ and/or decreases in response time $[8-12,14,16,19,20]$ during cognitive tasks. Physiological responses such as increased blood oxygen saturation $\left(\mathrm{SpO}_{2}\right)$ as well as decreased heart rate (HR) have supported the contribution of high-concentration oxygen administration to cognitive performance [8-12,14,16-20].

Many studies with a variety of cognitive tasks were performed using various verification methods to clarify how the administration of high-concentration oxygen enhances cognitive capability of normal people [8-19]. However, similar examinations with intellectually and developmentally disabled individuals have involved only one study using a visual matching task [20]. Further studies employing a variety of cognitive tasks as well as verification methods are needed in this population.

In this study, we investigated the effect of the administration of high-concentration oxygen on the memory function of individuals with intellectual and developmental disability. $\mathrm{SpO}_{2}$ and HR were measured, and the 0-back task was used as a cognitive task to focus on short-term memory, which is one of the most critical cognitive defects of those with intellectual and developmental disability.

\section{Methods}

The participants of this study were workers diagnosed by qualified psychiatrists as intellectually and developmentally disabled. The workers were all from a protective workshop of a community welfare foundation. Seven males $(28.9 \pm 1.8$ years of age) and seven females $(34.4 \pm$ 8.3 years of age) with an assessed disability level of $2.1 \pm$ 0.5 participated. Disability level was determined by a psychiatrist based on Diagnostic and Statistical Manual of Mental Disorders - 4th edition (DSM-IV) [21]. None of the participants reported having a periphery vascular flow system or respiratory system abnormality. The overall procedures and purposes of the experiments were explained to all the subjects and their guardians, and their guardians' consent was.

The protocol for the research project has been approved by Institutional Review Committee of Konkuk University within which the work was undertaken and that it conforms to the provisions of the Declaration of Helsinki.

The oxygen supply equipment (OXUS Co., Seoul, Korea) developed for this study consistently provided either $21 \%\left(21 \% \mathrm{O}_{2}, 78 \% \mathrm{~N}_{2}\right.$, and $\left.1 \% \mathrm{Ar}\right)$ or $92 \%\left(92 \% \mathrm{O}_{2}\right.$, $7 \% \mathrm{~N}_{2}$, and $1 \% \mathrm{Ar}$ ) oxygen in the air at a constant rate of $5 \mathrm{~L} / \mathrm{min}$. Oxygen was supplied to each subject through a mask to ensure a steady flow of oxygen with a constant concentration level.

The experiment was composed of two separate runs of a 0-back task. One run was conducted in the presence of $21 \%$ oxygen and the other with a $92 \%$ oxygen level. Every subject completed two runs where the order of runs was counterbalanced between $21 \%$ and $92 \%$ conditions. The second run started $1 \mathrm{~h}$ after the first one. Each run consisted of three phases: adaptation (1-min adaptation period after starting the oxygen administration), control (2-min stabilization period prior to the task), and 0-back task (2 min). During 2-min 0-back task phase, 20 numbers comprising one of five single-digit numbers $(0,1,2,3$, or 4$)$ were presented to the subject at 6-s intervals. The use of five single-digit numbers was in consideration of the intellectual level of the subjects. Each subject was asked to press the button when a certain number (0) was displayed. The ratio of the target number to the total numbers was 6:20. The 0-back tasks were presented on a monitor using E-prime (Psychology Software Tools, Sharpsburg, PA, USA). Prior to the start of the experiment, the subject was carefully instructed regarding the procedures and shown how to complete the task in the experiment.

The accuracy rate (\%) was determined as (number of correct answers $\div$ total number $) \times 100$. The response time in milliseconds (ms) for each facet of the 0-back test for each oxygen concentration was determined. We used a paired $t$-test (PASW ver. 18.0; SPSS, Chicago, IL, USA) to evaluate the differences in the accuracy rate and the response time between two oxygen concentration conditions.

An 8600 Series pulse oximeter (NONIN Medical Inc., Plymouth, MN, USA) was used to measure $\mathrm{SpO}_{2}$ (\%) and HR (bpm) from the left index finger of the subject. Average values of $\mathrm{SpO}_{2}$ and $\mathrm{HR}$ in each phase were obtained for each subject. The repeated measures of ANOVA (PASW ver. 18.0) were performed to evaluate the differences in $\mathrm{SpO}_{2}$ and $\mathrm{HR}$ between two oxygen concentrations (21\% vs. $92 \%)$ and between control and task phases. We excluded the adaptation phase out of the analysis.

\section{Results}

Figure 1 shows the results of behavioral accuracy and response time during the 0-back task with two different oxygen concentrations. Accuracy on average was $93.2 \pm 10.1$ for $21 \%$ and $97.1 \pm 4.7$ for $92 \%$ oxygen concentration (Figure 1a). The paired $t$-test revealed a significant difference in accuracy between oxygen concentrations $(t=-2.148, \mathrm{df}=13, P=0.050)$. Response time on average was $1,275.1 \pm 781.1 \mathrm{~ms}$ for $21 \%$ oxygen and 1,329.6 $\pm 873.5 \mathrm{~ms}$ for $92 \%$ oxygen (Figure $1 \mathrm{~b}$ ). Yet, no significant difference in response times was found between oxygen concentrations $(t=-0.590, \mathrm{df}=13, P>0.05)$. 


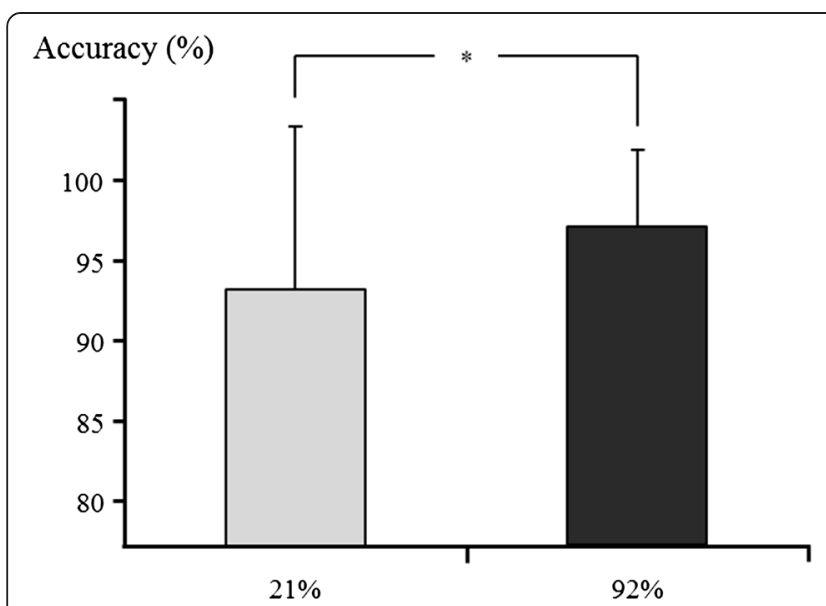

(a)

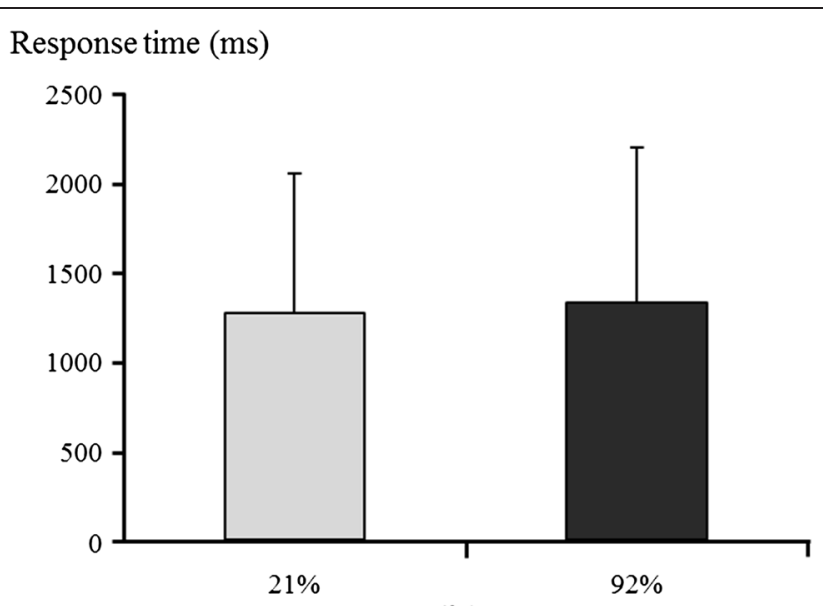

(b)

Figure 1 The $\mathbf{0}$-back task performance. (a) Accuracy and (b) response time for the administration of 21\% and 92\% oxygen concentrations.

Figure 2a shows the average $\mathrm{SpO}_{2}$ during control and task phases for $21 \%$ and $92 \%$ oxygen concentrations. Repeated measures of ANOVA revealed a significant difference in $\mathrm{SpO}_{2}$ between oxygen concentrations $(P<0.001)$ and between control and task phases $(P=0.018)$ (Table 1$)$. The administration of $92 \%$ oxygen led to greater $\mathrm{SpO}_{2}$ than $21 \%$ oxygen. Also, greater $\mathrm{SpO}_{2}$ was observed during the 0-back task phase than during the control. A significant interaction effect was shown between concentration and phase $(P=0.012)$, indicating a difference in trend of change in $\mathrm{SpO}_{2}$ at the two oxygen concentrations.

The mean HR of each phase (control and task) was shown in Figure $2 \mathrm{~b}$ according to oxygen concentration. Repeated measures of ANOVA revealed a significant difference in HR between oxygen concentrations $(P=0.015)$ as well as between control and task phases $(P<0.001)$ (Table 1). HR with $92 \%$ concentration was less than that with $21 \%$ concentration while HR was greater in the task

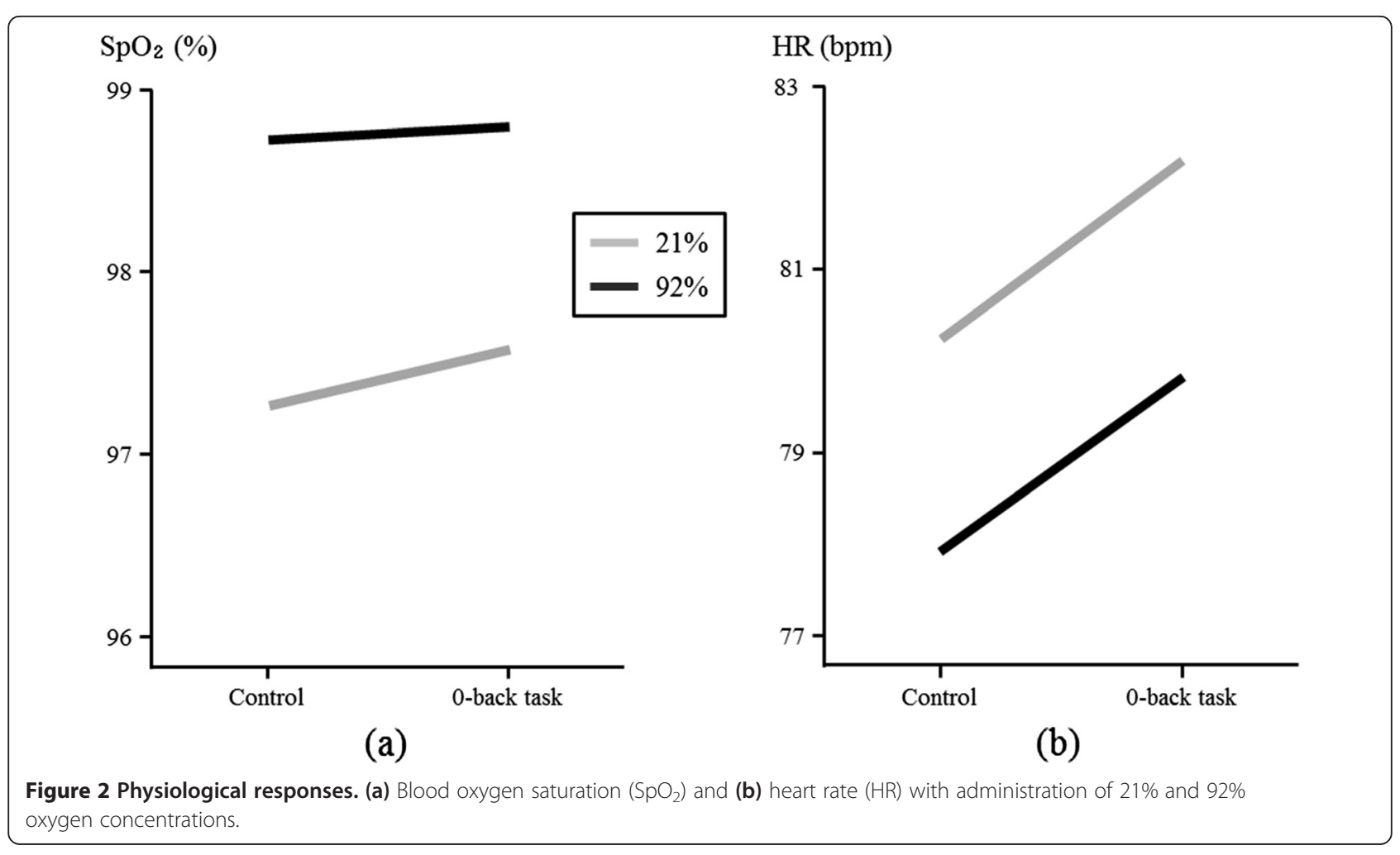


Table 1 ANOVA results of physiological responses for different conditions

\begin{tabular}{llccccc}
\hline & Source & Type III sum of squares & df & Mean square & \multicolumn{1}{c}{ Sig. } \\
\hline \multirow{2}{*}{$\mathrm{SpO}_{2}$} & Concentration & 25.246 & 1 & 25.246 & 189.239 & 0.000 \\
& Phase & 0.521 & 1 & 0.521 & 7.337 & 0.018 \\
& Concentration $\times$ phase & 0.191 & 1 & 0.191 & 8.625 & 0.012 \\
& Concentration & 77.002 & 1 & 77.002 & 7.880 & 0.015 \\
$\mathrm{HR}$ & Phase & 50.921 & 1 & 50.921 & 23.677 & 0.000 \\
& Concentration $\times$ phase & 0.006 & 1 & 0.006 & 0.003 & 0.959 \\
\hline
\end{tabular}

df, degrees of freedom. F, F value. Sig., significant.

phase than that in the control. No interaction effect was found between concentration and phase $(P>0.05)$.

\section{Discussion}

In the present study, we examined whether highconcentration (92\%) oxygen supply changed short-term memory performance, blood oxygen saturation, and heart rate in intellectually and developmentally disabled people.

Previous studies investigated the contribution of highconcentration oxygen supply to cognitive performance in healthy young and elderly individuals [8-20]. Especially, Kim et al. (2013) reported the improvement of visual matching task performance owing to highconcentration oxygen supply in people with intellectual and developmental cognitive deficit. The present study extended this finding by showing the improvement of 0-back task performance; an increase in accuracy was observed during exposure to the higher-concentration of oxygen. Therefore, it can be concluded that enriched oxygen can positively affect, at least in the short-term, the working memory of those with intellectual and developmental disability.

Presently, increased $\mathrm{SpO}_{2}$ was evident in the presence of $92 \%$ oxygen in comparison with $21 \%$ oxygen. It is consistent with a view that supply of higher-concentration oxygen increased the blood oxygen saturation level and consequently provided more oxygen to the brain, which in turn resulted in better performance of the 0-back task that requires active brain metabolism. Neural substrates engaged in the 0-back task may benefit from increased circulation of blood oxygen [13,15]. It is well understood that an increase in the supply of metabolic fuel, such as glucose, enhances the production of adenosine triphosphate (ATP) when cognitive demand is high. Such increases in ATP production can facilitate information processing involved in cognitive functions. These improvements of information processing may be reflected by enhancement of cognitive tasks [11]. To metabolize the fuel, the brain requires higher blood oxygen levels. Therefore, strong coupling between cognitive functions and the brain metabolism supports why a transient increase in oxygen concentration levels would be helpful.
In the present study, $\mathrm{SpO}_{2}$ during the 0-back task phase (cognitive processing phase) was increased compared with that during the control phase. This agrees with the results of previous studies [8,11,13,16-18,22,23], where oxygen requirements increased during cognitive processing. There was an interaction effect between oxygen concentration and phase because of the lower increase rate of $\mathrm{SpO}_{2}$ from control phase to 0-back task phase at $92 \%$ oxygen compared with $21 \%$ oxygen. This may be because sufficient oxygen is already being supplied for cognitive processing at the control phase when 92\% oxygen is administered.

Presently, there was a decrease in HR at $92 \%$ oxygen compared with $21 \%$ oxygen. Hyperoxia can reduce the resting heart rate [24]. Therefore, the present decrease in HR was likely due to hyperoxia [8-10,14,16-18]. HR during the 0-back task phase was increased compared with that during the control phase. This is consistent with the view that the cardiac load increases during cognitive processing, as has been reported $[8,9,14,16,18]$.

In conclusion, the administration of $92 \%$ oxygen increased 0-back task performance of intellectually and developmentally disabled people, in association with increased $\mathrm{SpO}_{2}$ and decreased $\mathrm{HR}$. The results are an objective and reliable demonstration of the positive effects of high-concentration oxygen supply on working memory in people with intellectual and developmental deficits, obtained during task performance and by recording changes in physiological signals.

The number of participants in the present study is not sufficiently large. Therefore, it would be necessary though to perform further studies with more participants to translate our results into clinical applications. Various cognitive abilities of intellectually and developmentally disabled people, such as information processing, attention, and verbal abilities, must be studied. Further studies need to be performed to examine the long-term and short-term effects of enriched oxygen on cognitive processing. Moreover, only two biosignals - $\mathrm{SpO}_{2}$ and heart rate - were observed to investigate the impact of high oxygen concentration on the body. However, in order to comprehensively and specifically analyze the effects of high oxygen concentration in terms of physiological anthropology, additional studies are required. These 
are based on various assessment methods, such as functional magnetic resonance imaging, electroencephalography, magnetoencephalography, blood flow, blood pressure, and heart rate variability; these can measure the response of the central nervous system and the peripheral nervous system in the brain and the whole body system.

\section{Competing interests}

The authors declare that they have no competing interests.

\section{Authors' contributions}

HSK, MHC, JHB, SJP, JCL, and UHJ were responsible for the data acquisition. HSK, SPK, and SCC were in charge of the study concept and design. SPK, HJK, YCC, and DWL provided technical help and help with the data analysis, HSK, SPK, and SCC guided the writing of the manuscript. All authors read and approved the final manuscript.

\section{Acknowledgements}

This work was supported by the Konkuk University in 2014.

\section{Author details}

'Department of Biomedical Engineering, BK21+ Research Institute of Biomedical Engineering, College of Biomedical \& Health Science, Konkuk University, 268 Chungwon-daero, Chungju Chungbuk-do 380-701, South Korea. ${ }^{2}$ Department of Design Human Engineering, Ulsan National Institute of Science and Technology, 50 UNIST-gil, Ulsan 689-798, South Korea. ${ }^{3}$ Department of Obstetrics \& Gynecology, Konkuk University, 268 Chungwon-daero, Chungju Chungbuk-do 380-701, South Korea. ${ }^{4}$ Department of Radiology, School of Medicine, Konkuk University, 268 Chungwon-daero, Chungju Chungbuk-do 380-701, South Korea. ${ }^{5}$ Department of Information \& Communication Engineering, Dongguk University, 30 Pildong-ro, Seoul 100-715, South Korea.

Received: 3 October 2014 Accepted: 19 January 2015 Published online: 20 February 2015

\section{References}

1. American Association on Intellectual and Developmental Disabilities: Definition of intellectual disability 2010, [http://aaidd.org/].

2. Kittler P, Krinsky-McHale SJ, Devenny DA. Sex differences in performance over 7 years on the Wechsler Intelligence Scale for children-revised among adults with intellectual disability. J Intellect Disabil Res. 2004;48:114-22.

3. Polloway EA, Patton JR. Strategies for teaching learners with special needs. 5th ed. Upper saddle River, NJ: Merrill/Prentice Hall; 1997.

4. Westling DL, Fox L. Teaching students with severe disabilities. 2nd ed. Upper saddle River, NJ: Merrill/Prentice Hall; 2000.

5. Liu T, Lin P, Chen Y, Wang J. Electroencephalogram synchronization analysis for attention deficit hyperactivity disorder children. Biomed Mater Eng. 2014;24:1035-9.

6. Kim HJ, Kim HS, Choi MH, Lee IH, Hong SP, You NR, et al. Response time of visual matching task and heart rate in children with attention deficit hyperactivity disorder (ADHD). Biomed Mater Eng. 2014;24:987-91.

7. Ellis NR, Deacon JR, Harris LA, Poor A, Angers D, Diorio MS, et al. Learning, memory, and transfer in profoundly, severely, and moderately mentally retarded persons. Am J Ment Defic. 1982;87:186-96.

8. Chung SC, Lim DW. Changes in memory performance, heart rate, and blood oxygen saturation due to 30\% oxygen administration. Int J Neurosci. 2008;118:593-606.

9. Choi MH, Kim HJ, Kim JH, Kim HS, Choi JS, Yi JH, et al. Correlation between cognitive ability measured by response time of 1-back task and changes of $\mathrm{SpO}_{2}$ by supplying three different levels of oxygen in the elderly. Geriatr Gerontol Int. 2013;13:384-7.

10. Moss MC, Scholey AB, Wesnes K. Oxygen administration selectively enhances cognitive performance in healthy young adults: a placebo-controlled double blind crossover study. Psychopharmacology. 1998;138:27-33.

11. Scholey AB, Moss MC, Neave N, Wesnes K. Cognitive performance, hyperoxia, and heart rate following oxygen administration in healthy young adults. Physiol Behav. 1999;67:783-9.

12. Winder R, Borrill J. Fuels for memory: the role of oxygen and glucose in memory enhancement. Psychopharmacology. 1998;136:349-56.
13. Chung SC, Tack GR, Lee B, Eom GM, Lee SY, Sohn JH. The effect of $30 \%$ oxygen on visuospatial performance and brain activation: an fMRI study. Brain Cogn. 2004;56:279-85.

14. Chung SC, Iwaki S, Tack GR, Yi JH, You JH, Kwon JH. Effect of $30 \%$ oxygen administration on verbal cognitive performance, blood oxygen saturation and heart rate. Appl Psychophysiol Biofeedback. 2006;31:281-93.

15. Chung SC, Sohn JH, Lee B, Tack GR, Yi JH, You JH, et al. The effect of transient increase in oxygen level on brain activation and verbal performance. Int J Psychophysiol. 2006;62:103-8.

16. Chung SC, Kwon JH, Lee HW, Tack GR, Lee B, Yi JH, et al. Effects of high concentration oxygen administration on n-back task performance and physiological signals. Physiol Meas. 2007;28:389-96.

17. Chung SC, Lee B, Tack GR, Yi JH, Lee HW, Kwon JH, et al. Physiological mechanism underlying the improvement in visuospatial performance due to 30\% oxygen inhalation. Appl Ergon. 2008;39:166-70.

18. Chung SC, Lee HW, Choi MH, Tack GR, Lee B, Yi JH, et al. A study on the effects of $40 \%$ oxygen on addition task performance in three levels of difficulty and physiological signals. Int J Neurosci. 2008;118:905-16.

19. Chung SC, Tack GR, Choi MH, Lee SJ, Choi JS, Yi JH, et al. Changes in reaction time when using oxygen inhalation during simple visual matching tasks. Neurosci Lett. 2009;453:175-7.

20. Kim HS, Choi MH, Kim HJ, Yeon HW, Yoon HJ, Lee $H$, et al. Changes in simple visual matching task performance and physiological signals in intellectually and developmentally disabled people due to administration of highly concentrated oxygen. NeuroRehabilitation. 2013;32:687-92.

21. American Psychiatric Association. Diagnostic and Statistical Manual of Mental Disorders, 4th Edition, Text Revision (DSM-IV-TR). Arlington, VA: American Psychiatric Association; 2000.

22. Backs RW, Seljos KA. Metabolic and cardiorespiratory measures of mental effort: the effects of level of difficulty in a working memory task. Int J Psychophysiol. 1994;16:57-68.

23. Turner JR, Carroll D. Heart Rate and Oxygen Consumption during Mental Arithmetic, a Video Game, and Graded Exercise: Further Evidence of Metabolically-Exaggerated Cardiac Adjustments? Psychophysiology. 1985:22:261-7.

24. Lodato RF, Jubran A. Response time, autonomic mediation, and reversibility of hyperoxic bradycardia in conscious dogs. J Appl Physiol. 1993;749:634-42.

\section{Submit your next manuscript to BioMed Central and take full advantage of:}

- Convenient online submission

- Thorough peer review

- No space constraints or color figure charges

- Immediate publication on acceptance

- Inclusion in PubMed, CAS, Scopus and Google Scholar

- Research which is freely available for redistribution

Submit your manuscript at www.biomedcentral.com/submit 